\title{
Differentiation and Central Projections of Peripheral Sensory Cells with Action-Potential Block in Drosophila Mosaics
}

\author{
Martin G. Burg and Chun-Fang Wu \\ Department of Biology, University of lowa, lowa City, lowa 52242
}

The ultrastructural differentiation and central projection of identified bristle mechanosensory neurons were examined in Drosophila mutants lacking action potentials. Two mutations, para $^{t s I}$ and nap ${ }^{t s}$, are known to block axonal conduction in centrally located neurons at high temperatures. Their effects on epithelial sensory cells, which are derived from imaginal disks during pupation, have not been determined. Furthermore, the para $^{t s i}$ nap $^{t s}$ double-mutant flies are lethal at all temperatures; thus the synergistic effect of these mutations on neurons has not yet been studied. It is possible to examine the above questions in genetic mosaics. By monitoring a reflex response involving identified bristle sensory cells, we found that the 2 mutations exert similar effects on these epithelial sensory cells as seen in central neurons. This also indicates that the action potential mechanisms in both epithelial sensory cells and central neurons are under similar genetic control.

The para $a^{t s I}$ nap ${ }^{s}$ double-mutant sensory cells in mosaics are nonfunctional at all temperatures, providing an opportunity to examine, at the single cell level, the development of neurons with activity block. Ultrastructural specializations typical of epithelial sensory cells were found in the double-mutant cells. Cobalt backfilling experiments showed that central projections of these nonfunctional sensory cells were not altered, as compared with the active contralateral sensory cells. Therefore, blockage of the action potential mechanism in individual sensory cells has no effect on their pathfinding and arborization.

Sensory axons differentiate and grow from the periphery, forming specific connections in the CNS. The role of nerve activity in the pathfinding and arborization of neurons is not well understood. Connectivity in vertebrate sensory systems has been shown to be maintained and modified by activity (Harris, 1981; Hubel et al., 1977; Sanes and Constantine-Paton, 1983). For example, blockade of $\mathrm{Na}^{+}$channel-dependent electrical activity using TTX affects the formation and maintenance of specific sensory connections in retinotectal systems of several vertebrates (Archer et al., 1982; Harris, 1984; Meyer, 1982; Reh and ConstantinePaton, 1985).

Few studies of activity dependence in the development of invertebrate sensory systems have been reported (Palka, 1984). Experience-dependent changes in the CNS of Drosophila have recently been detected (Technau, 1984), suggesting that this plasticity may be activity dependent. The experiments described

\footnotetext{
Received Oct. 22, 1985; revised Feb. 18, 1986; accepted Apr. 11, 1986.

We thank Dr. B. Ganetzky for providing stocks and helpful discussion, Dr. S. Green for providing technical suggestions, Drs. J. Denburg and A. Komatsu for comments on the manuscript, Mrs. R. Williams for advice in EM work, and Miss A. Chan for assistance in drawings. This work was supported by NIH Grants NS00675, NS15350, and NS18500 (C.-F.W.). M.G.B. was supported by NIH Predoctoral Genetics Traineeship GM07091.

Correspondence should be addressed to Dr. Chun-Fang Wu at the above address.

Copyright (C) 1986 Society for Neuroscience $0270-6474 / 86 / 102968-09 \$ 02.00 / 0$
}

in this paper attempted to examine directly the activity dependence in the formation and maintenance of connectivity within sensory projections in an invertebrate nervous system.

In Drosophila, mutations are available that eliminate nerve activity (Hall, 1982). Genetic mosaics can also be produced, in which only a portion of the fly is phenotypically mutant (Hall, 1978; Hotta and Benzer, 1972). Using this mosaic system, it is possible to study at the single cell level the effects of blockade of activity on sensory cell morphology, whilc surrounding cells remain functionally active. Two mutations, para $^{t s I}$ (paralytic, temperature-sensitive) (Suzuki et al., 1971) and nap $p^{t s}$ (no-actionpotential, temperature-sensitive) (Wu et al., 1978), are separately located on the first and second chromosomes, respectively. They both result in a temperature-sensitive paralytic phenotype, causing action potential failure in axons at a high temperature (above $29^{\circ} \mathrm{C}$ for para $^{t s I}$ and $34^{\circ} \mathrm{C}$ for napts). These mutations have been suggested to affect the voltage-sensitive $\mathrm{Na}^{+}$channel, on the basis of physiological (Siddiqi and Benzer, 1976; Wu and Ganetzky, 1980; Wu et al., 1978), pharmacological (Suzuki and Wu, 1984; Wu et al., 1983), and toxin binding (Jackson et al., 1984; Kauvar, 1982) studies.

The above results concerning the para ${ }^{t s t}$ and nap $p^{t s}$ mutations were obtained using centrally located neurons. It is not known whether these 2 mutations also affect epithelial sensory cells, which represent a developmentally distinct set of excitable cells that differentiate in imaginal disks during pupation. The combined effects of paratst with nap ${ }^{t s}$ on neurons have not been studied, because they are known to interact synergistically, resulting in lethality of the organism even at $17^{\circ} \mathrm{C}$ (Ganetzky, 1984; Wu and Ganetzky, 1980).

In this paper, we examine these questions by utilizing a stereotyped reflex behavior of decapitated flies in which stimulation of an identified sensory cell elicits a scratching response from a specific leg (Vandervorst and Ghysen, 1980). We have created small-patch mosaics containing a single mutant mechanosensory cell, identifiable by the associated mutant bristle, which are both derived from a common progenitor cell (Lawrence, 1966). Thus, the function of the mutant sensory cell can be tested by comparing reflex responses from the mutant bristle with responses from normal bristles, which evoke identical responses within each fly. Using this system, we have determined the effects of para ${ }^{t s t}$ and $n a p^{s}$ on the function of these cells. In addition, this mosaic system provides a unique opportunity to characterize and examine the differentiation, pathfinding, and projection formation of inactive para $^{t s I}$ nap ${ }^{t s}$ double-mutant sensory cells, which is impossible to do in a nonviable doublemutant hy. Preliminary accounts of this work have appeared previously (Burg and Wu, 1984, 1985).

\section{Materials and Methods}

Generation of mosaics

Genetic mosaics were found in female flies in which 1 of the $2 \mathrm{X}$-chromosomes was an unstable ring-X chromosome, $\operatorname{In}(1) w^{\nu C}$ (Hinton, 1955). 


$$
\begin{aligned}
& q q \frac{y w \operatorname{spl}}{\ln (1)^{v C}} \times \frac{y \text { chopara }{ }^{(s)}}{Y} \sigma^{\prime} \\
& \text { random loss of } \ln (/)_{w} v C \\
& \text { in developing } q \text { progeny } \\
& \frac{y \text { cho paratst }}{O} / / \frac{y \text { cho paratsl }}{\ln \left(1 / \mathrm{w}^{\mathrm{vC}}\right.}
\end{aligned}
$$

Figure 1. Construction of para ${ }^{s s}$ mosaics. Female flies containing the ring-X chromosome $\left(\operatorname{In}(1) w^{\nu} \mathrm{C}\right)$ were mated with para $^{\text {ts } /}$ males. Genetic markers on the other $\mathrm{X}$ chromosomes used in the maintenance of the ring-X strain were yellow body $(y)$, white facets $(w)$, and split bristles $(s p l)$. Loss of the ring-X chromosome in female progeny produces patches of hemizygous tissue ( $y$ cho para $a^{s l} / O$, detectable by recognizing $y$ and cho on the cuticle) surrounded by heterozygous tissue (y cho para ${ }^{t s t}$ In $\left.(I) w^{v C}\right)$. Progeny of other genotypic constructions are not shown.

When this ring- $X$ chromosome is lost during development, mosaic flies are produced that contain patches of hemizygous $(\mathrm{X} / \mathrm{O})$ male tissue surrounded by normal female tissue. When the remaining $\mathrm{X}$-chromosome carries recessive mutations, they will be expressed in the hemizygous patches of tissue in the phenotypically normal heterozygous tissue. Mutant patches in mosaics can be of varying size: The later during development that the ring-X chromosome is lost, the smaller the mutant patch will be (Garcia-Bellido and Ripoll, 1978; Garcia-Bellido et al., 1979; Zalokar et al., 1980). In these experiments, the X-linked recessive mutations $y$ (yellow, 1-0.0) and cho (chocolate, 1-13.0) were used (Lindsley and Grell, 1968). These mutations cause yellow body color and chocolate facets, so that the entire cuticle of the fly could be examined and patches of mutant cuticle could be recognized.

Since para $^{t s t}$ is X-linked, mosaics containing patches of para $a^{t s t}$ mutant tissue were produced by recombining $y$ and cho to $p a r a^{s s}$. This method of producing mosaic flies containing $y$ cho para ${ }^{t s t}$ cuticle is shown in Figure 1. In this particular cross, females were produced containing In $(1) w^{v C}$ (ring-X) and $y$ cho para ${ }^{\text {sst }}$ chromosomes. In $21 \%$ of these 1176 females ( $y$ cho parats $/ \operatorname{In}(1) w^{\mu c}$ ), a loss of the ring-X chromosome occurred that produced visible cuticle mosaicism. In at least $25 \%$ of these mosaics, the para ${ }^{\text {st }}$ patches were small, containing only 1-2 bristles (macrochaetae), which result from a late loss of the ring-X chromosome in the imaginal disc.

Since $n a p^{t s}$ is located on the second chromosome, nap $p^{t s}$ mutant patches could not readily be produced using the ring-X system. Instead, para $a^{t s I}$ nap $p^{t s}$ double-mutant patches in mosaics were examined. As seen in Figure 2, this was done by producing para $^{\text {ss }}$ mutant patches in flies that were homozygous for napts. The resulting tissue in the mutant patch is doubly mutant $\left(\mathrm{para}^{t s} / O\right.$; nap $\mathrm{p}^{t s} /$ nap $\left.^{t s}\right)$, while the rest of the fly would be phenotypically napts but not para $^{t s l}$ ( para $^{t s t} / \operatorname{In}(1) w^{w C} ; n a p^{t s} / n a p^{t s}$ ). In this manner, lethality in double-mutant flies can be circumvented by producing small-sized patches of double-mutant tissue in mosaic flies. In this study, cuticle mosaicism occurred in $9 \%$ of 2600 flies, with $67 \%$ of these mosaics having small patches (see above) of double-mutant tissue containing $1-2$ bristles. All flies in this study were raised at $22^{\circ} \mathrm{C}$.

\section{Bristle reflex}

Mosaic flies that contained a small mutant patch on the dorsal mesothorax were used for the bristle reflex test. These flies behaved normally even at restrictive temperatures (above $29^{\circ} \mathrm{C}$ for parats and any temperature for para $^{s s}$ nap ${ }^{t s}$ ), confirming that the mutant patch did not include a significant amount of internal nerve tissue. They were anesthetized with ether and decapitated, using petroleum jelly to seal the wound. Two hours of recovery time were allowed in a moist environment. A decapitated fly stands still (Fig. 3A) and exhibits a stereotypic leg reflex behavior (Vandervorst and Ghysen, 1980). Reflex responses were evoked by moving the bristle back and forth several times with an eyelash, triggering the appropriate leg to scratch the bristle touched. Such flies have routinely responded for up to 3 days, but all tests in this report were conducted within $24 \mathrm{hr}$ of decapitation. The bristles tested were those that normally elicit positive responses with a frequency greater than $70 \%$ upon single stimulation (Vandervorst and Ghysen,

$$
\begin{aligned}
& \text { qq } \frac{y w s p l}{\ln \left(1 / W^{v C}\right.} ; \frac{n a p^{t s}}{n a p^{t s}} \times \frac{y \text { choparats }}{n a p+Y} ; \frac{n a p^{\prime s}}{n a p^{t s}} \sigma^{\prime \prime} \sigma^{\prime \prime} \\
& \text { random loss of } \ln (/)_{w} v C \\
& \text { in developing } q \text { progeny } \\
& \frac{y \text { cho parats }}{O}, \frac{\text { napts }}{\text { napts }} / / \frac{y \text { cho parats } /}{\ln \left(1 / W^{v C}\right.}, \frac{\text { napts }}{\text { napts }}
\end{aligned}
$$

Figure 2. Construction of para ${ }^{2 s t}$ nap ${ }^{2 s}$ mosaics. Fermale flies homozygous for nap $p^{i s}$ and containing the ring-X chromosome $\left(\operatorname{In}(1) w^{k C}\right)$ were mated to males that carry both para ${ }^{t s I}$ on the $\mathrm{X}$ chromosome and nap $p^{t s}$ on the second chromosome. The $Y$ chromosome (nap ${ }^{+} Y$ ), an insertional translocation $(\mathrm{T}(\mathrm{Y} ; 2) \mathrm{L} 12)$, carries one normal copy of the nap locus, $n a p^{+}$, which is necessary to overcome the lethal effect of the parats napts double-mutant combination (Ganetzky, 1984). Loss of the ring-X chromosome in female progeny produces patches of double-mutant tissue ( $y$ cho $\mathrm{para}^{t s} / O$; nap ${ }^{t s} /$ nap $^{t s}$ ), surrounded by phenotypically nap $p^{t s}$ tissue (y cho para $a^{i s l} / \operatorname{In}(1) w^{\text {cc; }}$; nap $p^{i s} /$ nap $^{i s}$ ).

1980). Therefore, multiple stimulations will always produce clear-cut results to distinguish between responsive and nonresponsive bristles. In addition to the mutant bristle, surrounding phenotypically normal bristles that would elicit identical responses from the same leg were tested (Fig. 4). Tests on these and other phenotypically normal bristles served as a control to eliminate internal mosaicism that involved the remaining portion of the CNS.

Reflex tests of para $^{\text {ss }}$ mosaics were performed on a Peltier stage (ColePalmer, model 3832, or Cambion, model 809-3010-01), so that accurate control and rapid changes of temperature could be performed to determine the effects on the reflex behavior at both the permissive $\left(23^{\circ} \mathrm{C}\right)$ and restrictive $\left(30^{\circ} \mathrm{C}\right)$ temperatures. Reflex tests done with para $^{t s I}$ nap ${ }^{t s}$ mosaic flies were performed at 17 and $25^{\circ} \mathrm{C}$, because the control patches ( para $^{t s l} / \operatorname{In}(1) w^{\nu c} ;$ nap $\left.p^{t s} / n a p^{t s}\right)$ do not elicit reliable responses above $25^{\circ} \mathrm{C}$

\section{Electron-microscopic analysis of identified bristle sensory cells}

Small mutant patches of homozygous para ${ }^{t s}$ nap ${ }^{\text {ts }}$ tissue in day old mosaic flies were used for electron-microscopic analysis. The mosaic flies were dissected and fixed in Karnovsky's fixative and postfixed in $1 \% \mathrm{OsO}_{4}$ (in $0.1 \mathrm{~m}$ sodium cacodylate buffer). The specimens were then stained en bloc using 2\% uranyl acetate and embedded in Spurr's resin (Polysciences, Inc.). Serial thin sections were stained with lead citrate and later observed using a Zeiss EM10A EM.

\section{Cobalt backfilling of sensory cells}

Mosaic flies containing para ${ }^{t s t}$ nap $p^{t s}$ double-mutant sensory cells were used to investigate the effects of activity blockade on the central projection of the sensory cell. Several considerations make using doublemutant sensory cells more suitable than performing temperature shifts on para $^{t s t}$ or nap ${ }^{t s}$ mosaics to block action potentials. First, the para ${ }^{t s t}$ mutants are known to partially regain movement after prolonged exposure to high temperature, i.e., $30^{\circ} \mathrm{C}$ (Grigliatti et al., 1972; Suzuki et al., 1971). Thus, a simple temperature shift regiment will not block activity during the entire period of development. Second, the restrictive temperature for nap is $34^{\circ} \mathrm{C}$, and prolonged exposure to this temperature during development is not desirable because it is close to temperatures that induce a heat-shock response. However, the para $^{\iota s}$ nap $p^{\prime s}$ double-mutant sensory cells are nonfunctional even at low temperatures, as shown in Table 1B.

Single mechanosensory cell projections in the thoracic ganglia were visualized by using a modified cobalt backfilling technique. One- to fiveday-old small-patch mosaics, containing only one double-mutant bristle, were used for all backfill experiments. A small drop of a $2 \% \mathrm{CoCl}_{2}$ solution containing $1.5 \mu \mathrm{g} / \mathrm{ml}$ BSA (Sigma) was placed on the cuticle where a single macrochaeta bristle was pulled or cut. The fly was then placed in a humid chamber for $30-45 \mathrm{~min}$. After incubation, the ganglia and brain were dissected from the fly and immersed in a diluted solution $(1: 40)$ of ammonium sulfide for $5 \mathrm{~min}$. Following a saline rinse, 


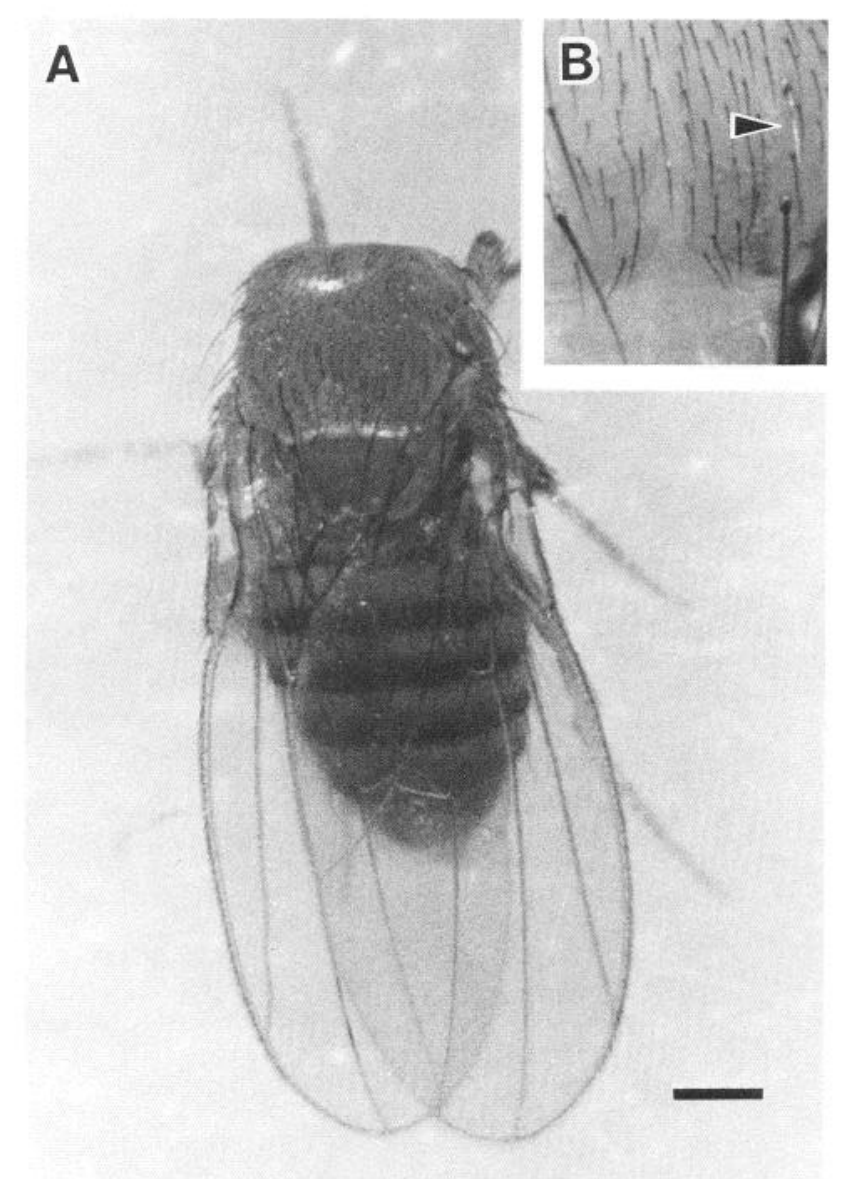

Figure 3. Photomicrograph of a decapitated small-patch mosaic used in the bristle reflex experiment. $A$, Decapitated flies stand upright and are motionless (exposure time, $5 \mathrm{sec}$ ). $B$, This particular mosaic fly contains only a single yellow bristle (arrow). Bar, $300 \mu \mathrm{m}(A), 110 \mu \mathrm{m}$ (B).

specimens were fixed for 1-3 hr using Carnoy's fixative. Afterward, a silver-intensification procedure (Bacon and Altman, 1977) was used to visualize the sensory cell's projection. Specimens were observed as a whole-mount in immersion oil using a compound microscope (Zeiss Photomicroscope I). Backfill of a single sensory cell was indicated by the staining of a single axon in the nerve root, prior to the axon's initial branch point. Photographs in serial planes of focus were taken to obtain detailed morphology of the sensory cell's projection. Camera lucida drawings were made for each stained sensory cell, so that the entire projection could be analyzed.

\section{Results}

\section{Blockade of sensory cell function by the para ${ }^{\text {ts }}$ mutation}

Previous studies of parats ${ }^{t s}$ have been performed on neurons derived from centrally located neuroblasts. Small-patch mosaic flies, as shown in Figure $3 B$, were generated in order to test the effect that para $a^{t s l}$ may have on the function of bristle sensory cells, which arise from imaginal disks during pupation and share a common progenitor cell with bristle-forming cells. These smallpatch para $^{s t}$ mosaics were tested for their reflex behavior at low $\left(23^{\circ} \mathrm{C}\right)$ and high $\left(30^{\circ} \mathrm{C}\right)$ temperatures to determine whether temperature-sensitive blockade of the reflex behavior occurred. Bristles on the dorsal thorax are identifiable and, within certain regions of the mesothorax and humerus, will elicit reflex responses of prothoracic and metathoracic legs, as shown in Figure 4 (also, see Vandervorst and Ghysen, 1980). The phenotypically normal (heterozygous) bristles surrounding the mutant patch

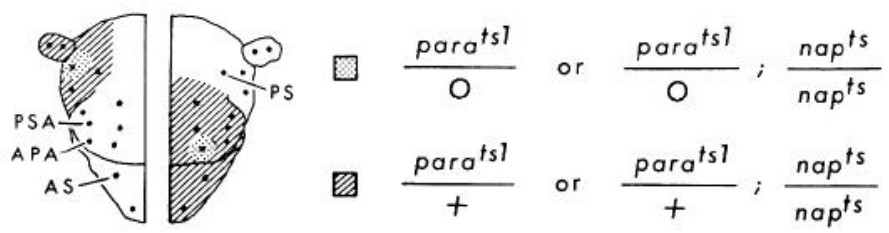

Figure 4. Macrochaeta bristles of the dorsal thorax that elicit reflex responses from specific legs. Shown is a map of the dorsal thorax, with macrochaeta bristles represented by dots. Territories for pro- and metathoracic leg responses are shown on separate halves for clarity. Macrochaetae within the shaded region on the left half, including the humerus and an anterior portion of the notum, elicit responses from the left prothoracic leg. Macrochaetae within the shaded region on the right half, including posterior portions of the notum and the entire scutellum, elicit responses from the right metathoracic leg. Shown for each region described above is an example of a small mosaic patch, identifiable by color, including a single mutant bristle (dotted region). In the experiment, when the yellow mutant bristle fails to elicit a reflex response but the surrounding black normal bristles do elicit a response, this indicates that the sensory cell underlying the yellow bristle is mutant, whereas the remaining portions of the reflex circuit are functional. Shown are the locations of the $P S$ (presutural), $P S A$ (posterior supra-alar), $A P A$ (anterior post-alar), and $A S$ (anterior scutellar) bristles of the dorsal thorax, which were the bristles most frequently studied.

were also tested for the ability to elicit an identical reflex response of the same leg at both temperatures $\left(23^{\circ}\right.$ and $\left.30^{\circ} \mathrm{C}\right)$. This control was performed to ensure that no other portion of the reflex circuit contained para ${ }^{t s}$ tissue in the mosaics tested.

The exact circuit underlying the reflex behavior in Drosophila has not been established. A small group of motorneurons innervating the leg (Ikeda and Kaplan, 1970) is excited by the sensory cells directly or by interneurons indirectly.

In all the small-patch mosaics containing para $^{t s l}$ tissue, only the mutant sensory cells failed to elicit a response at the high temperature (Table 1A), while at the low temperature, responses were elicited. In contrast, surrounding normal bristles elicited responses at both temperatures. This result conclusively shows that the bristle mechanosensory cells are affected by $\operatorname{para}^{t s l}$ much like centrally located neurons are (Siddiqi and Benzer, 1976; Wu and Ganetzky, 1980). This also suggests that the action potential mechanisms used by these 2 sets of cells are under similar genetic control.

\section{Activity blockade in para $^{\text {ts } 1}$ nap ${ }^{\text {ts }}$ bristle sensory cells}

Since para $^{t s l}$ nap $^{t s}$ double-mutant flies are lethal, the combined effects of these mutations on neuronal function have not been studied. To examine these effects, we produced parats ${ }^{t s}$ mosaic patches in nap $^{t s}$ homozygous flies (see Materials and Methods and Fig. 2). In such mosaics the patch size of doubly mutant tissue was small (Fig. $3 B$ ), and only occasionally were large patches produced, consistent with a previous report (Ganetzky, 1984). The mosaic flies that contained large patches of parats napts cuticle mostly had reduced movement even at low $\left(17^{\circ} \mathrm{C}\right)$ temperatures, presumably because of internal mosaicism involving the CNS.

Results from the reflex behavior experiment performed on mosaics containing small patches of paratst nap ts doubly mutant tissue are shown in Table $1 \mathrm{~B}$. At $25^{\circ} \mathrm{C}$, which is below the restrictive temperature for either para $^{t s l}$ or $n a p^{t s}$, no reflex responses were elicited from double-mutant bristles in mosaics $(n=36)$. In comparison, the surrounding bristles that were heterozygous for para ${ }^{t s l}$ but homozygous for nap ${ }^{t s}$ (see Fig. 4) did elicit homologous responses in 30 of the mosaics tested. Identical results were obtained when the experiment was performed at $17^{\circ} \mathrm{C}$, demonstrating that the blockade of sensory cell function by para $^{t s l}$ nap $^{t s}$ is not temperature dependent (Table 1B).

Among 36 small-patch mosaics available for testing, 6 did 

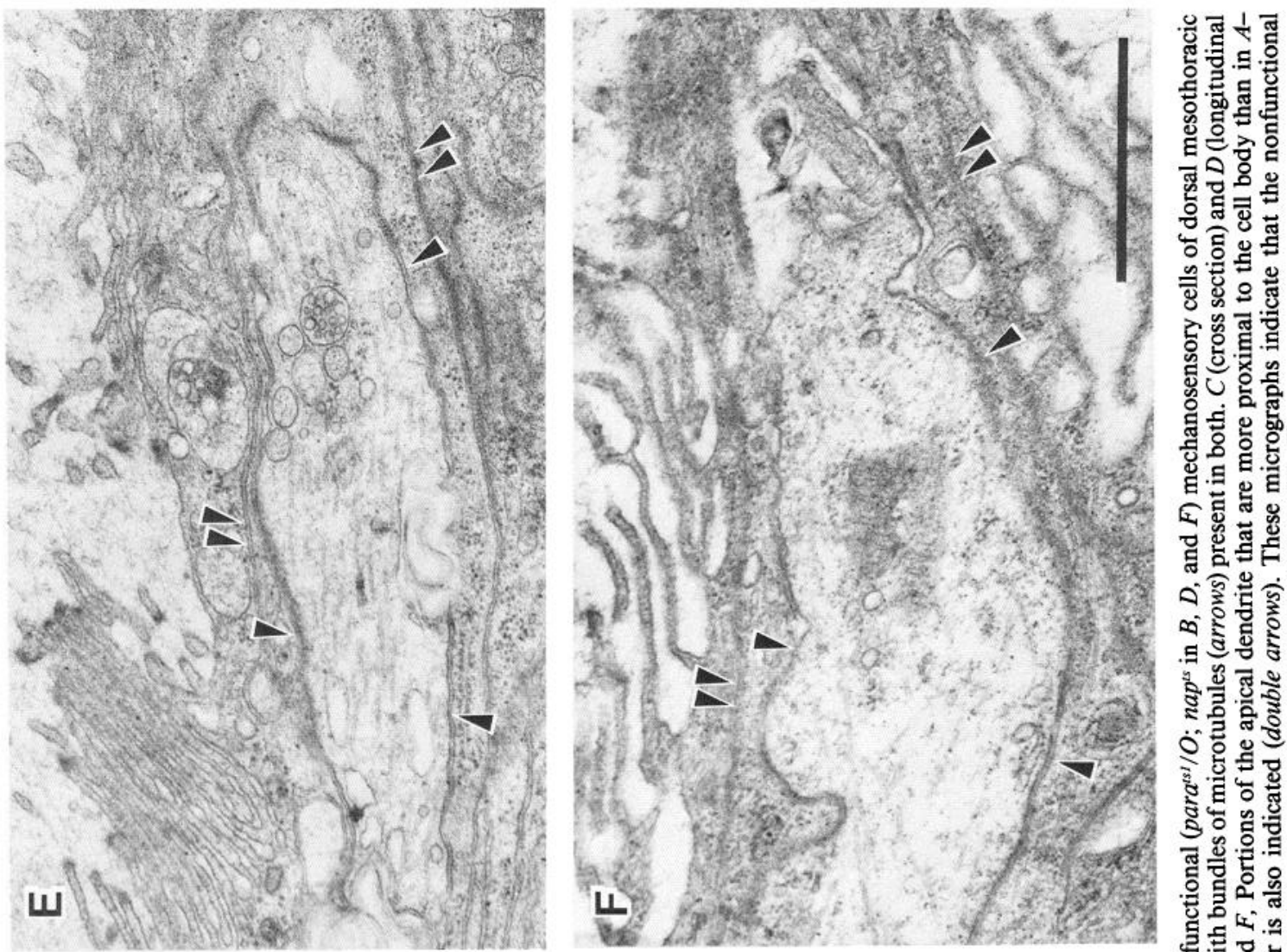

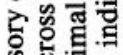

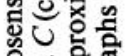

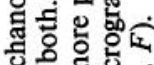

的.

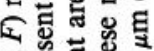

골

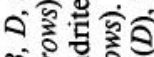

.

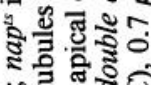

원월

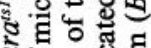

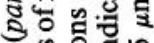

플응

형형응 قैس
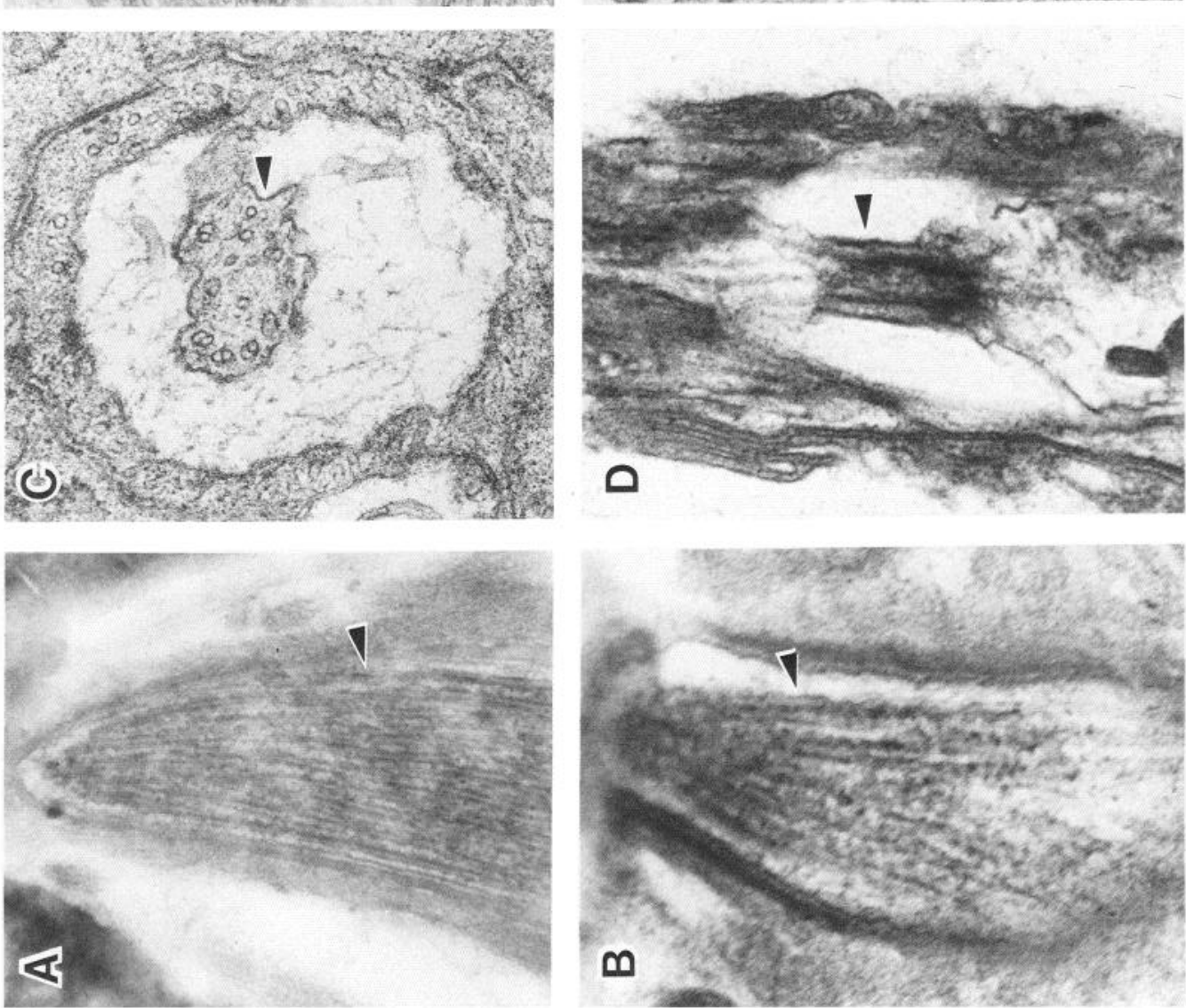

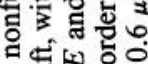

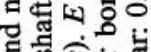

ज的氜

(1).

훠

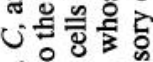

굴 홍

는 㟧

马् क

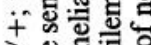

言害完它

ธे

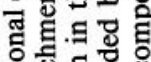

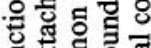

䎡昆

⿷.

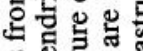

웜를

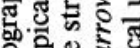

安定

舟

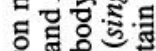

넝

州

过

实高

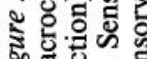

这焉宓 
Table 1. Bristle reflex of decapitated small-patch mosaic flies

\begin{tabular}{|c|c|c|c|c|}
\hline \multirow[b]{2}{*}{ Bristle genotype } & \multirow[b]{2}{*}{$\begin{array}{l}\text { Temperature } \\
\text { tested }\left({ }^{\circ} \mathrm{C}\right)\end{array}$} & \multicolumn{3}{|c|}{ No. flies tested } \\
\hline & & $\begin{array}{l}\text { Respon- } \\
\text { sive } \\
\text { bristles }\end{array}$ & $\begin{array}{l}\text { Nonre- } \\
\text { sponsive } \\
\text { bristles }\end{array}$ & Total \\
\hline \multicolumn{5}{|l|}{ A } \\
\hline \multirow[t]{2}{*}{$\operatorname{para}^{t s I} / O$} & 23 & 50 & 0 & 50 \\
\hline & 32 & 0 & 50 & 50 \\
\hline \multirow[t]{2}{*}{$\operatorname{paras}^{s s} /+$} & 23 & 50 & 0 & 50 \\
\hline & 32 & 50 & 0 & 50 \\
\hline \multicolumn{5}{|l|}{ B } \\
\hline \multirow{2}{*}{$\operatorname{para}^{t s L} / O ; n a p^{t s}$} & 17 & 0 & 36 & 36 \\
\hline & 25 & 0 & 36 & 36 \\
\hline \multirow[t]{2}{*}{ para $^{t s l} /+; n a p^{t s}$} & 17 & 30 & $6^{*}$ & 36 \\
\hline & 25 & 30 & $6 *$ & 36 \\
\hline
\end{tabular}

Results of bristle reflex behavioral experiments with small-patch mosaics containing 1-2 para $^{s s}$ (A) or para ${ }^{s s}$ nap ${ }^{s s}$ (B) bristles. Shown in different rows are the total number of mosaic patches in different flies and the genotypes of mutant (para ${ }^{s t} / O$ for $\mathrm{A}$ and $p a r a a^{s t} / O$; nap $p^{s s}$ for $\mathrm{B}$, where $n a p^{t s}$ is abbreviated for homozygous napts/

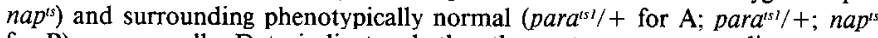
for B) sensory cells. Data indicate whether the mutant or surrounding sensory cells elicit responses at the temperatures tested.

Of the $6 \mathrm{para}^{\text {sil }} /+; n a \mathrm{p}^{t s}$ flies indicated by the asterisks, no responses were elicited from any bristle on the fly; see explanation in text. Results show that the sensory cells are affected by para $^{(s)}$ in a temperature-dependent fashion (A) and that para $a^{s t}$ $n a p^{\prime s}$ double-mutant sensory cells are inactive, regardless of the temperature tested (B). Responses elicited by the surrounding sensory cells indicate that the mutant patch involves only the sensory cell, but not the remaining components of the reflex circuit.

not elicit responses from the surrounding bristles (see asterisks in Table 1B). Furthermore, no responses were elicited from any bristle on these 6 flies. The reasons for this result are unknown, although 2 possibilities exist. One is that an internal mosaic patch of para $^{t s I}$ napts tissue could be present that prevents the fly from reacting to any stimulation given. A second possibility is that these mosaic flies may not recover as readily as wildtype flies from the decapitation procedure, due to the dominant interaction of para $^{t s t}$ with nap ${ }^{t s}$ (Ganetzky, 1984). Flies heterozygous for para ${ }^{t s l}$ and homozygous for nap ${ }^{t s}\left(\right.$ para $^{t s 1} / \operatorname{In}(1) w^{v c}$; $n a p^{s} /$ nap $\left.^{\prime s}\right)$ have a reduced viability and become paralyzed at a lower temperature $\left(26^{\circ} \mathrm{C}\right)$ than either $\operatorname{para}^{t s t}\left(29^{\circ} \mathrm{C}\right)$ or nap $\left(34^{\circ} \mathrm{C}\right)$.

In summary, the combined effect of para $^{t s t}$ nap ${ }^{t s}$ can be conclusively demonstrated in these sensory cells, at all temperatures tested. It is of interest to ask whether the failure of para $^{t s t}$ nap $p^{t s}$ sensory cells to initiate a reflex response is due to the prevention of sensory cell differentiation by this genetic interaction.

\section{Differentiation of para $^{\text {tst }}$ nap ${ }^{\text {ts }}$ sensory cells}

To investigate whether any ultrastructural components of the cell were absent due to this double-mutant genotype, EM serial section analysis was performed on 5 phenotypically normal $\left(\mathrm{para}^{t s l} / \operatorname{In}(1) \mathrm{w}^{\nu \mathrm{C}}\right.$; nap ${ }^{i s} /$ nap $^{i s}$ ) sensory cells and 4 double-mutant $\left(\right.$ para $^{t s l} / O$; nap $\left.p^{t s} / n a p^{t s}\right)$ sensory cells from small-patch mosaics.

Figure $5, A$ and $B$, compares the apical portion of the sensory cell in the bristle apparatus from both a normal and a doublemutant bristle apparatus, respectively. The attachment of the apical portion of the sensory cell to the bristle shaft is similar, containing bundles of microtubules in both cases. Minor differcnces may be attributed to the plane and thickness of sectioning. In all 4 double-mutant sensory cells examined, this region of attachment was similar to that of the control cell.

The modified ciliary body structure within this sensory cell is shown in cross section and longitudinal section in Figure 5,

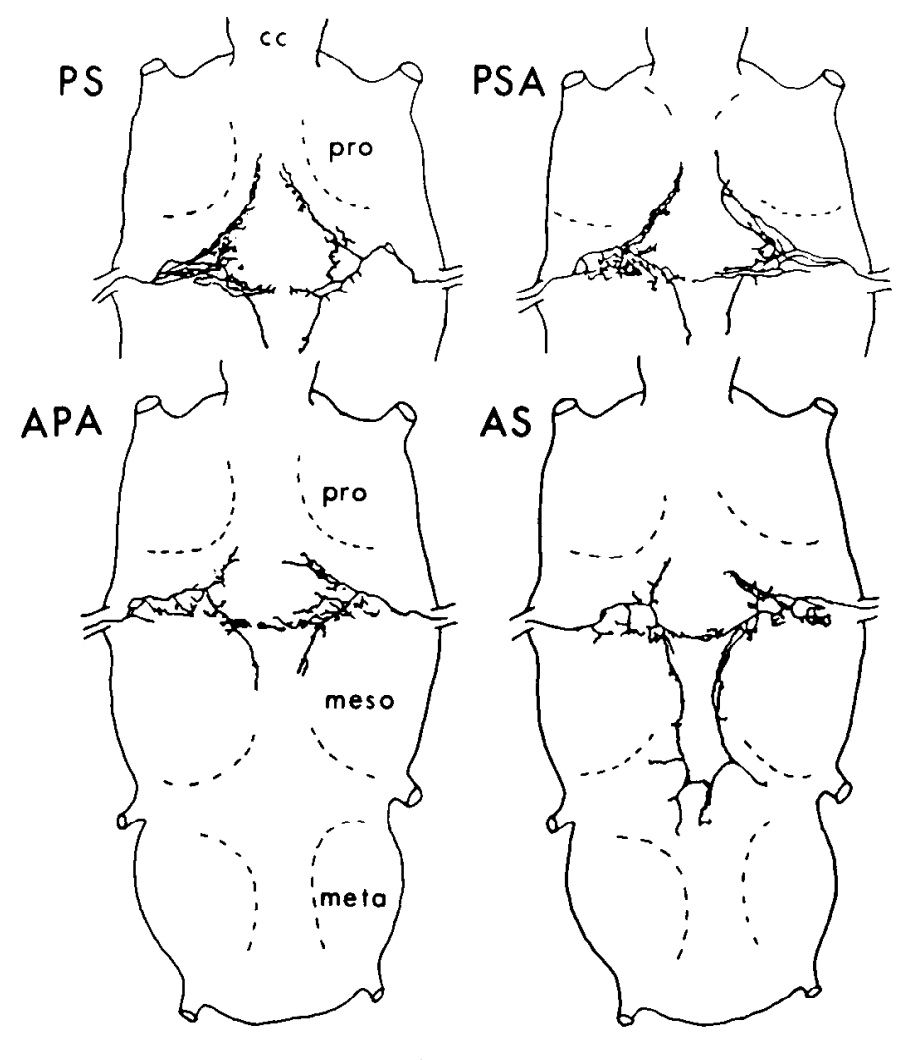

Figure 6. Maps of identified bristle sensory cell central projections revealed by cobalt backfilling. This and the following figures present dorsal vicws of paircd projections in the thoracic ganglia of the sensory cells identified in Figure 4. Paired backfills (a double mutant sensory cell and its contralateral control cell) for the PS, PSA, APA, and AS sensory cells are traced from 4 individual animals. These projections reside on the ventral surface of the ganglia, terminating between the neuromeres. Individual neuromeres, demarcated by dashed lines, can be observed and serve as landmarks. The point of entry for each axon is within the posterior dorsal mesothoracic nerve root. Other cut ventral nerve roots for each individual neuromere are shown for clarity. Cervical connective ( $c c$ ) and prothoracic (pro), mesothoracic (meso), and metathoracic (meta) neuromeres are marked. Bar, $100 \mu \mathrm{m}$.

$C$ (control) and $D$ (double-mutant), showing microtubules within a modified ciliary body located in both sensory cells. This is typical of the arrangement in the apical dendritic portion of the sensory cell (Reed et al., 1975; Thurm, 1968). Figure 5, $E$ and $F$, shows that the proximal dendritic region of control and double-mutant sensory cells have similar ultrastructural components. The neurilemma cell can also be seen surrounding the sensory cell in both figures.

Two normal bristle sensory cells in wild-type animals have also been examined and yielded similar results. In micrographs of all sensory cells analyzed, there were no distinct morphological differences between the control and double-mutant sensory cells, even though the double-mutant cells apparently fail to propagate electrical activity. Thus, the compound effect of para $^{i s t}$ and $n a p^{t s}$ does not prevent the ultrastructural differentiation of organelles typical of mechanoreceptor cells, although the functioning of these double-mutant organelles requires further physiological examination.

\section{Central projection of para $^{\text {ts } 1}$ nap ${ }^{\text {ts }}$ sensory cells}

By using mosaic flies containing small patches of para ${ }^{t s t}$ nap $p^{t s}$ double-mutant tissue, it was possible to determine, at the single cell level, the effects of the absence of action potential activity 

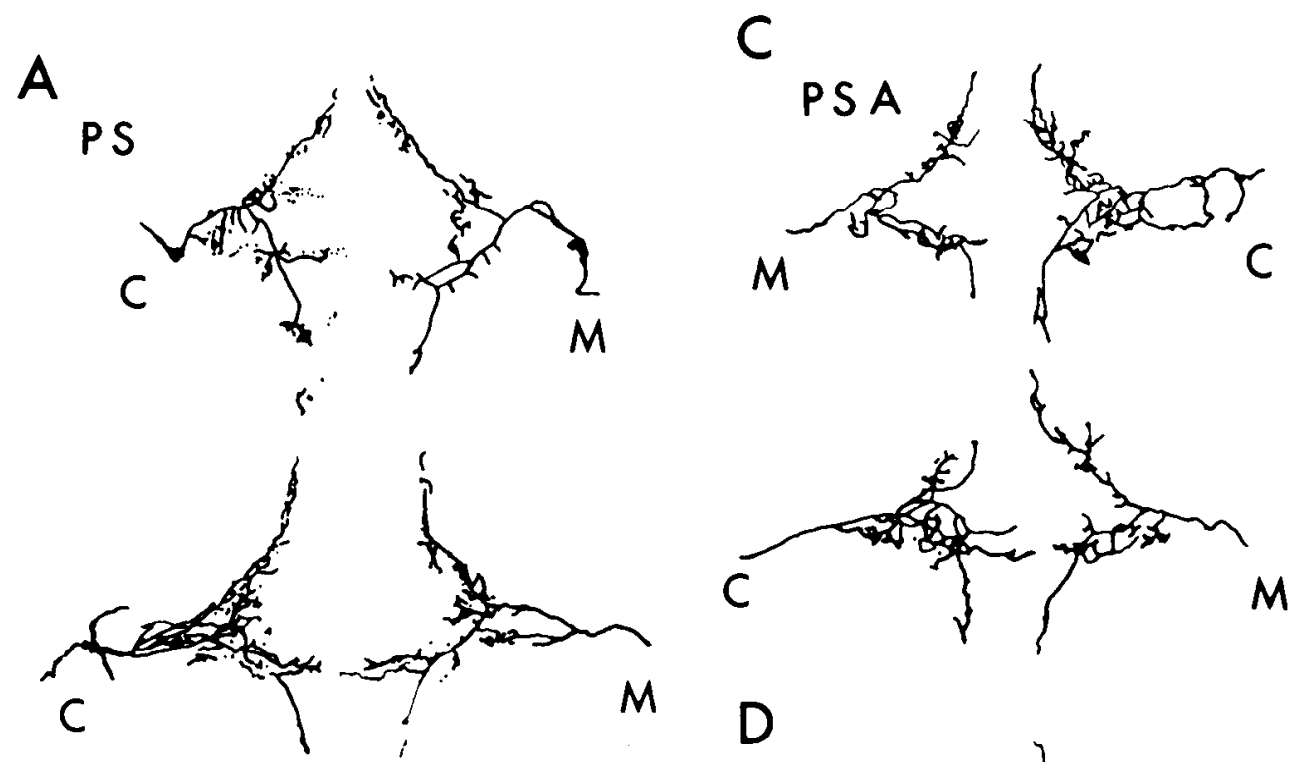

M

B

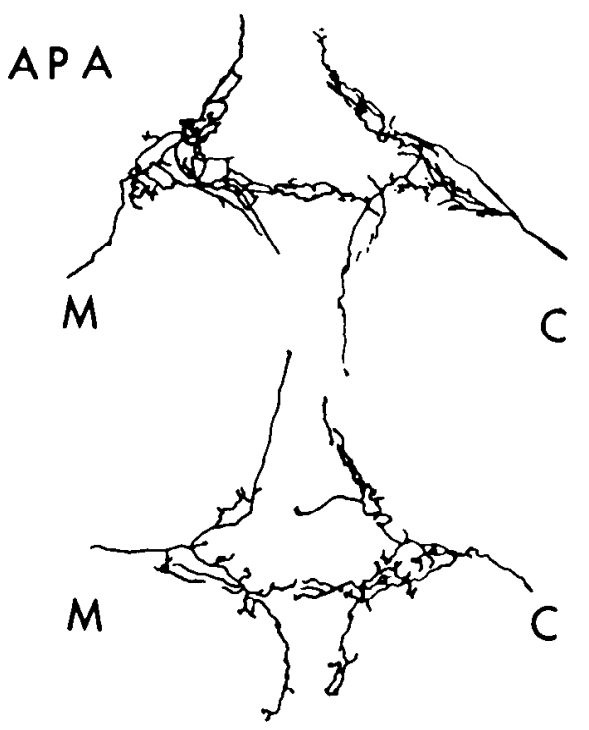

D
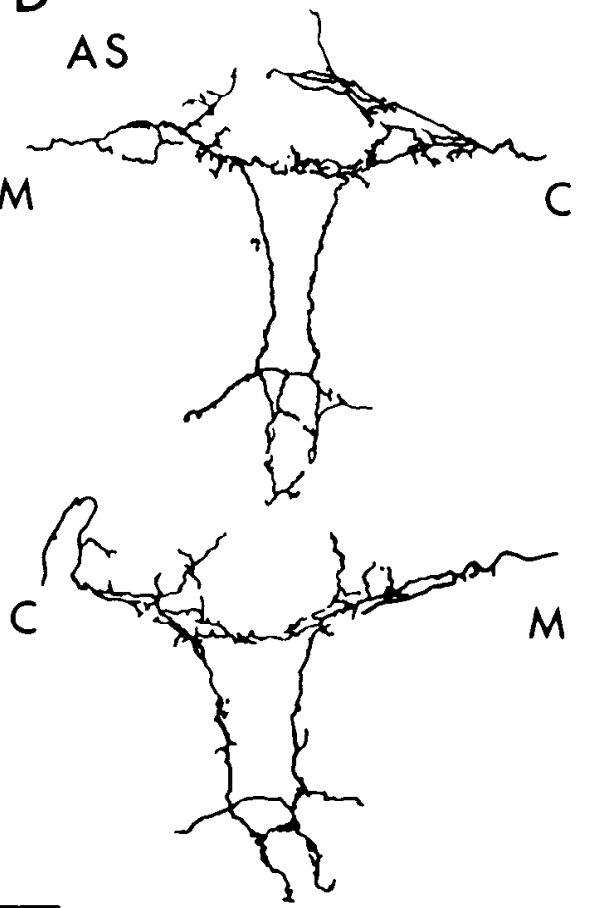

Figure 7. Detailed camera lucida tracings of projections from para ${ }^{i s}$ napts nonfunctional and contralateral control bristle sensory cells in smallpatch mosaic flies. Two representative pairs are presented from backfills of the 4 bristles identified in Figure 4, each pair consisting of a double-mutant $(M)$ and a contralateral control (C) sensory cell projection. $A$, Projections from PS sensory cells; $B$, APA cells; $C$, PSA cells; $D$, AS cells. Note posterior extension of the AS cell's projection in $D$. Bar, $100 \mu \mathrm{m}$. on the final projection and central arborization of these sensory cells. Although the reflex response elicited for each bristle is reproducible from fly to fly (Vandervorst and Ghysen, 1980), the dendritic branching of these cells may be variable in their details. Therefore, for each double-mutant sensory cell that was backfilled, the contralateral phenotypically normal cell was also backfilled to serve as a control.

Figure 4 maps the location of identified bristles whose sensory cell projections (shown in Fig. 6) have been more extensively studied. The sensory cell axon enters the thoracic ganglia via a branch of the posterior dorsal mesothoracic nerve root. This nerve root contains axons from other sensory structures of the mesothoracic segment, such as the wing (Ghysen, 1980; Ghysen and Janson, 1979; Palka and Schubiger, 1979). Upon entering the thoracic ganglia, the axons begin to branch, forming characteristic arborizations for each identified sensory cell. These axons traverse between the pro- and mesothoracic neuromeres and then project anteriorly and posteriorly, close to the ventral surface of the thoracic ganglia (Fig. 6; see also Ghysen, 1978).
For the PSA (posterior supra-alar) and APA (anterior post-alar) sensory cells (see Fig. 4), there are dorsally located projections as well, which appear to be more variable in pattern and are stained less frequently than ventrally located projections.

Mosaics produced by ring- $X$ loss contain male tissue within a female fly. As a control for sexual dimorphism of these projections, bilateral cobalt backfilling was also performed on 3 different types of mosaics, in which both the sensory cell in the small male hemizygous patch and the surrounding female sensory cells remained active. The mosaics constructed for this purpose contained hemizygous patches of the following genotypes: (1) para $^{t s l} / O$; nap $p^{t s} /+,(2)+/ O$; nap $p^{t s} /+$, or (3) $+/ O$. These patches were surrounded by female tissue without ring-X loss (i.e., $O$ replaced by $\left.\operatorname{In}(1) w^{\nu C}\right)$. We found no indication of sexual dimorphism between the projections of male and female mechanosensory cells of the dorsal thorax (data not shown).

These experiments also served as a control for the effects that varying the para $^{t s l}$ and nap $p^{t s}$ genetic backgrounds could have on sensory cell projection. We have compared the detailed tracings 
of AS sensory cell projections having these different genotypes. No distinguishable differences could be found among the projections, demonstrating that our observations of the consequences of activity blockade were not complicated by other unknown factors associated with a specific genetic background.

Figure 7 contains detailed camera lucida drawings of representative paired projections, assembled from different mosaics, of the 4 identified cells presented in Figure 6. There appear to be greater degrees of variability in the arborization of the identified sensory cells between mosaics than within each mosaic backfilled (compare to Figs. 6 and 8). Nevertheless, as shown in Figure 7, the projections of the double-mutant (M) and the control (C) sensory cells have similar major branching patterns. These results are based on successful backfilling of 23 APA (10 $\mathrm{M}$ and $13 \mathrm{C}$ ), 23 PSA ( $\mathrm{M}$ and $16 \mathrm{C}), 5 \mathrm{PS}$ ( $3 \mathrm{M}$ and $2 \mathrm{C}$ ), and 10 AS ( $3 \mathrm{M}$ and $7 \mathrm{C}$ ) sensory cells (for location of cells, see Fig. 4).

Mosaics in which both the double-mutant and contralateral control sensory cells were successfully backfilled have been difficult to obtain ( 28 out of 113 attempts). Two such successful backfills are shown in Figure 8. Despite a relatively small sample size, the bilateral backfills even more convincingly demonstrate the similarity between the projections of functional and nonfunctional sensory cells.

The variability in this backfill technique may prevent detection of differences in minor details. However, at the present level of resolution, no differences were detected between the central projections of the nonfunctional para $^{t s}$ nap ${ }^{t s}$ sensory cell and the functional sensory cell.

\section{Discussion}

\section{Effects of para $^{\text {tsl }}$ and nap $^{\text {ts }}$ on sensory cell function and differentiation}

The results show that both $\operatorname{para}^{t s I}$ and nap ${ }^{t s}$ mutations affect the function of sensory cells within the mechanosensory apparatus. Signal conduction in these cells is reversibly blocked by para $a^{t s}$ and is absent at all temperatures tested in para $^{t s l}$ nap ${ }^{t s}$ doublemutant cells, as in central neurons. This suggests that the genetic mechanism responsible for the generation of action potentials is similar in both epithelial mechanosensory cells and central neurons.

Previous studies in nematodes provide examples where some mutations that block function of mechanosensory cells did not prevent normal ultrastructural differentiation (Chalfie and Sulston, 1981). Using genetic mosaics to circumvent the lethality resulting from the para $^{t s l} n a p^{t s}$ interaction, it was possible to demonstrate that the absence of excitability does not prevent sensory cell differentiation in Drosophila as well.

It should be pointed out that simple elimination of action potentials may not be the only mechanism that can account for the observed functional blockade in the double-mutant sensory cells. Variations from this simple condition must be considered and await further investigation. First, defects in synapse formation cannot be ruled out by the cobalt backfilling technique. Although synaptic function in nap ${ }^{t s}$ and para $^{t s l}$ single mutants has been shown to be physiologically normal (Wu and Ganetzky, 1980; Wu et al., 1978), no information regarding the doublemutant synaptic function is yet available. Second, these mutations may not affect all cell types uniformly. Subthreshold or local electrical activity could still be present in these para $^{t s 1}$ nap $^{t s}$ sensory cells. Recently, Nelson and Baird (1985) have indirectly shown that in neither nap ${ }^{t s}$ nor para $^{t s l}$ single mutants is action potential propagation in the cervical giant fiber completely blocked. Presumably, these single-gene mutations reduce but do not completely eliminate the $\mathrm{Na}^{+}$current (Jackson et al., 1984; Suzuki and Wu, 1984). The giant fiber, with its larger diameter and hence greater space constant, would have an in-
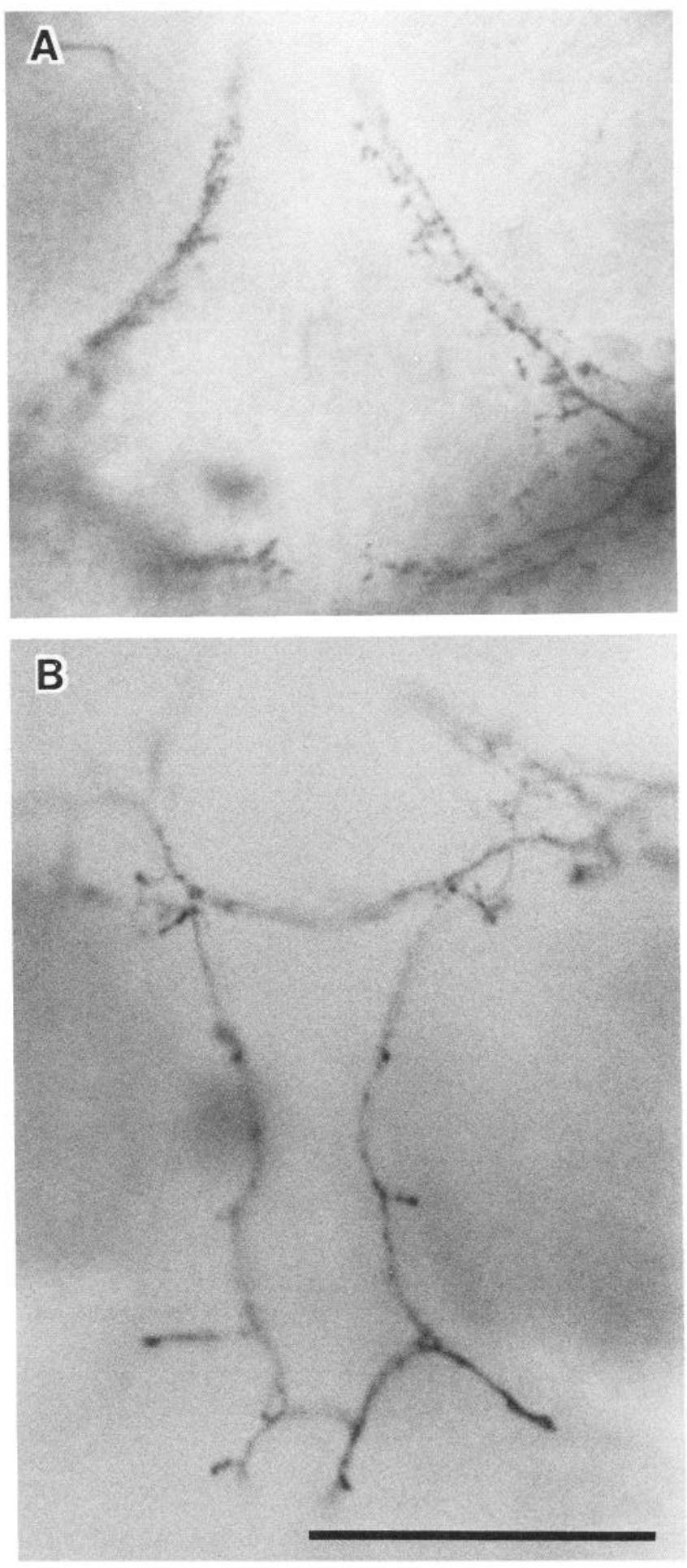

Figure 8. Photomicrographs of 2 paired backfills of para ${ }^{t s t}$ nap ${ }^{t s}$ double-mutant and contralateral control bristle sensory cells in small-patch mosaic flies. $A$, PS sensory cell pair, mutant projection on right. $B, \mathrm{AS}$ sensory cell pair, mutant projection on left. Portions of these projections are not in focus. Figure 6 contains the complete projections of these same 2 preparations. Note the symmetry in the paired projections. Bar, $50 \mu \mathrm{m}$.

creased safety margin. Furthermore, intracellular recordings have demonstrated that $\mathrm{Ca}^{2+}$ current contributes to the generation of action potentials in the giant fiber (Tanouye et al., 1981). These factors would make the giant fiber less affected than other axons by the para $^{t s l}$ or $n a p^{t s}$ mutations (Ganetzky and Wu, 1985; 
Siddiqi and Benzer, 1976; Wu et al., 1978). No physiological recordings from the $p a a^{t s t} n a p^{t s}$ double-mutants have been obtained because of the lethal interaction described above. Last, the effects of mutations may depend on developmental stages. Developing sensory cells during pupation may employ a different action potential mechanism, although this is unlikely since developing larval or prepupal neurons in culture have been shown to be affected by parats and napts (Suzuki and Wu, 1984).

\section{Activity dependence of sensory cell projection}

The mosaic system offers certain advantages in studies of the activity dependence of the central projection formation and maintenance of sensory cells. Unlike other experimental systems, the development of a single identified inexcitable cell can be studied in a phenotypically normal environment (for a discussion of mosaics, see Palka, 1979). In previous studies on the dependence of the generation and maintenance of connectivity on activity, TTX was applied to an entire population of cells to eliminate action potentials (Harris, 1984; Meyer, 1982; Reh and Constantine-Paton, 1985). It is difficult to selectively affect a small group of cells in this manner.

Our results indicate that lack of action potentials does not alter the sensory cell central projection. This finding is in contrast to observations on vertebrate sensory systems, in which terminal branching critically depends on activity. For example, in the retinotectal system of the frog, application of TTX increases the branching of the retinal ganglion cell projection in the tectal lamina (Reh and Constantine-Paton, 1985). Meyer (1982) and Harris (1984) have shown that TTX alters the retinotectal projections in other vertebrates. Therefore, the fixed wiring of insect sensory projections may employ cues other than the modulation of nerve activity.

There have been previous demonstrations of the effects of sensory deprivation on projections of sensory cells in invertebrates. For example, unilateral cercal removal in the cricket causes a redistribution of the bilateral central arborization of the remaining cercal sensory cell. The distribution of terminal branching of the remaining cell is shifted towards the sensorydeprived side (Murphy and Lemere, 1984). In our study, without physically removing the sensory cell, differences in branching patterns between functional and nonfunctional sensory cells have not been detected. Therefore, the observed effects of sensory deprivation in the cricket may not be attributable to an absence of activity but rather the physical absence of the contralateral sensory cell.

It should be noted that our results do not necessarily rule out a possible role of nerve activity in the maintenance of arbors as well as in the process of directed growth and final projection of these sensory cells. Different combinations of multiple parallel mechanisms could provide the essentials for normal development. Sensory cells may use other chemical or physical cues in the environment. For example, chemical signals from developing or degenerating cells, electrical fields set up by other neurons (Patel and Poo, 1984), or the mere physical presence of neighboring cells (Silver and Sidman, 1980) could provide important extrinsic influences.

This study can be extended to investigate the effect of other mutations in Drosophila that alter specific cellular properties (Hall, 1982) important to the development of the nervous system. For example, it will be possible to investigate the effect of blocking different ionic conductances during development. Using the mosaic system, these types of problems can be investigated at a single cell level in a normally developing system in vivo.

\section{References}

Archer, S. M., M. W. Dubin, and L. A. Stark (1982) Abnormal development of kitten retino-geniculate connectivity in the absence of action potentials. Science $217: 743-745$.
Bacon, J. P., and J. S. Altman (1977) A silver intensification method for cobalt-filled neurons in wholemount preparations. Brain Res. 138: 359-363.

Burg, M. G., and C.-F. Wu (1984) Blockage of a reflex response in genetic mosaics by temperature sensitive mutations: Effects on sensory cells derived from imaginal discs of Drosophila. Soc. Neurosci. Abstr. 10:513.

Burg, M. G., and C.-F. Wu (1985) Central projections of peripheral sensory cells lacking functional activity in Drosophila mosaics. Soc. Neurosci. Abstr. 11:917.

Chalfie, M., and J. Sulston (1981) Developmental genetics of the mechanosensory neurons of Caenorhabditis elegans. Dev. Biol. 82: 358371.

Ganetzky, B. (1984) Genetic studies of membrane excitability in Drosophila: Lethal interaction between two temperature-sensitive mutations. Genetics 108: 897-911.

Ganetzky, B., and C.-F. Wu (1985) Genes and membrane excitability in Drosophila. Trends Neurosci. 8: 322-326.

Garcia-Bellido, A., and P. Ripoll (1978) Cell lineage and differentiation in Drosophila. In Genetic Mosaics and Cell Differentiation, W. J. Gehring, ed., pp. 119-156, Springer-Verlag, New York.

Garcia-Bellido, A., P. A. Lawrence, and G. Morata (1979) Compartments in animal development. Sci. Am. 241: 102-110.

Ghysen, A. (1978) Sensory neurons recognise defined pathways in Drosophila central nervous system. Nature 274: 869-872.

Ghysen, A. (1980) The projection of sensory neurons in the central nervous system of Drosophila: Choice of the appropriate pathway. Dev. Biol. 78: 521-541.

Ghysen, A., and R. Janson (1979) Sensory pathways in Drosophila central nervous system. In Development and Neurobiology of Drosophila. O. Siddiqi, P. Babu, L. M. Hall, and J. C. Hall, eds., pp. 247265, Plenum, New York.

Grigliatti, T., D. T. Suzuki, and R. Williamson (1972) Temperaturesensitive mutations in Drosophila melanogaster X. Developmental analysis of the paralytic mutation, para $^{t^{\prime \prime-3}-3}$. Dev. Biol. 28: 352-371.

Hall, J. C. (1978) Behavioral analysis in Drosophila mosaics. In Genetic Mosaics and Cell Differentiation, W. J. Gehring, ed., pp. 259305, Springer-Verlag, New York.

Hall, J. C. (1982) Genetics of the nervous system in Drosophila. Q. Rev. Biophys. 15: 223-479.

Harris, W. (1981) Neural activity and development. Annu. Rev. Physiol. 43: 689-710.

Harris, W. A. (1984) Axonal pathfinding in the absence of normal pathways and impulse activity. J. Neurosci. 4: 1153-1162.

Hinton, C. W. (1955) The behavior of an unstable ring chromosome of Drosophila melanogaster. Genetics 40: 951-961.

Hotta, Y., and S. Benzer (1972) Mapping of behavior in Drosophila mosaics. Nature 240:527-535.

Hubel, D. H., T. N. Wiesel, and S. LeVay (1977) Plasticity of ocular dominance columns in monkey striate cortex. Phil. Trans. R. Soc. Lond. [Biol.] 278: 377-409.

Ikeda, K., and W. D. Kaplan (1970) Patterned neural activity of a mutant Drosophila melanogaster. Proc. Natl. Acad. Sci. USA 66:765772.

Jackson, F. Rob, S. D. Wilson, G. R. Strichartz, and L. M. Hall (1984) Two types of mutants affecting voltage-sensitive sodium channels in Drosophila melanogaster. Nature 308: 189-191.

Kauvar, L. M. (1982) Reduced $\left[{ }^{3} \mathrm{H}\right]$-tetrodotoxin binding in the nap paralytic mutant of Drosophila. Mol. Gen. Genet. 187: 172-173.

Lawrence, P. A. (1966) Development and determination of hairs and bristles in the milkweed bug, Oncopeltus fasciatus. J. Cell Sci. 1:475498

Lindsley, D. L., and E. H. Grell (1968) Genetic variations of Drosophila melanogaster, Carnegie Institute, Washington, DC.

Meyer, R. L. (1982) Tetrodotoxin blocks the formation of ocular dominance columns in goldfish. Science 218: 589-591.

Murphy, R. K., and C. A. Lemere (1984) Competition controls the growth of an identified axonal arborization. Science 228: 1352-1355.

Nelson, J. C., and D. H. Baird (1985) Action potentials persist at restrictive temperatures in temperature sensitive paralytic mutants of adult Drosophila. Soc. Neurosci. Abstr. 11: 313.

Palka, J. (1979) Mutants and mosaics: Tools in insect developmental neurobiology. Soc. Neurosci. Symp. 4: 209-227.

Palka, J. (1984) Precision and plasticity in the insect nervous system. Trends Neurosci. 7: 455-456.

Palka, J., and M. Schubiger (1979) Formation of central patterns by 
receptor cell axons in Drosophila. In Development and Neurobiology of Drosophila., O. Siddiqi, P. Babu, L. M. Hall, and J. C. Hall, eds., pp. 223-246, Plenum, New York.

Patel, N. B., and M.-M. Poo (1982) Orientation of neurite growth by extracellular electric fields. J. Neurosci. 2: 483-496.

Reed, C. T., C. Murphy, and D. Fristrom (1975) The ultrastructure of the differentiating pupal leg of Drosophila melanogaster. Wilhelm Roux's Arch. 173: 285-302.

Rch, T. A., and M. Constantinc-Paton (1985) Eyc-spccific scgregation requires neural activity in three-eyed Rana pipiens. J. Neurosci. 5. $1132-1143$.

Sanes, D. H., and M. Constantine-Paton (1983) Altered activity patterns during development reduce neural tuning. Science 221: $1183-$ 1185 .

Siddiqi, O., and S. Benzer (1976) Neurophysiological defects in temperature-sensitive paralytic mutants of Drosophila melanogaster. Proc. Natl. Acad. Sci. USA 73: 3253-3257.

Silver, J., and R. S. Sidman (1980) A mechanism for the guidance and topographic patterning of retinal ganglion cell axons. J. Comp. Neurol. 189: 101-111.

Suzuki, D. T., T. Grigliatti, and R. Williamson (1971) Temperaturesensitive mutations in Drosophila melanogaster: A mutation (paras) causing reversible adult paralysis. Proc. Natl. Acad. Sci. USA 68 . $890-893$

Suzuki, N., and C.-F. Wu (1984) Altered sensitivity to sodium chan- nel-specific neurotoxins in cultured neurons from temperature-sensitive paralytic mutants of Drosophila. J. Neurogenet. 1: 225-238.

Tanouye, M., A. Ferrus, and S. C. Fujita (1981) Abnormal action potentials associated with the Shaker locus of Drosophila. Proc. Natl. Acad. Sci. USA 78: 6548-6552.

Technau, G. M. (1984) Fiber number in the mushroom bodies of adult Drosophila melanogaster depends upon age, sex, and experience. J. Neurogenet. 1: 113-126.

Thurm, U. (1968) Steps in the transducer process of mechanoreceptors. Symp. Zool. Soc. Lond. 23: 199-216.

Vandervorst, P., and A. Ghysen (1980) Genetic control of sensory connections in Drosophila. Nature 286: 65-67.

Wu, C.-F., and B. Ganetzky (1980) Genetic alteration of nerve membrane excitability in temperature-sensitive paralytic mutants of Drosophila melanogaster. Nature 286: 814-816.

Wu, C.-F., B. Ganetzky, L. Y. Jan, Y. N. Jan, and S. Benzer (1978) A Drosophila mutant with a temperature-sensitive block in nerve conduction. Proc. Natl. Acad. Sci. USA 75: 4047-4051.

Wu, C.-F., N. Suzuki, and M.-M. Poo (1983) Dissociated neurons from normal and mutant Drosophila larval central nervous system in cell culture. J. Neurosci. 3: 1888-1899.

Zalokar, M., I. Erk, and P. Santamaria (1980) Distribution of ring-X chromosomes in the blastoderm of gynandromorphic $D$. melanogaster. Cell 19: 133-141. 